\title{
Myriam Robic, Hellénismes de Banville: mythe et modernité
}

Ida Merello

\section{Q OpenEdition}

1 Journals

\section{Edizione digitale}

URL: http://journals.openedition.org/studifrancesi/6365

DOI: $10.4000 /$ studifrancesi.6365

ISSN: 2421-5856

\section{Editore}

Rosenberg \& Sellier

\section{Edizione cartacea}

Data di pubblicazione: 1 novembre 2010

Paginazione: 573

ISSN: 0039-2944

\section{Notizia bibliografica digitale}

Ida Merello, «Myriam Robic, Hellénismes de Banville: mythe et modernité», Studi Francesi [Online], 162 (LIV | III) | 2010, online dal 30 novembre 2015, consultato il 13 janvier 2021. URL: http:// journals.openedition.org/studifrancesi/6365 ; DOI: https://doi.org/10.4000/studifrancesi.6365

Questo documento è stato generato automaticamente il 13 janvier 2021.

\section{(c) (i) $\odot$}

Studi Francesi è distribuita con Licenza Creative Commons Attribuzione - Non commerciale - Non opere derivate 4.0 Internazionale. 


\title{
Myriam Robic, Hellénismes de Banville: mythe et modernité
}

\author{
Ida Merello
}

\section{NOTIZIA}

MYRIAM ROBIC, Hellénismes de Banville: mythe et modernité, Paris, Champion 2010, pp. 557.

1 Un esame attento dello stato della critica permette all'A. di individuare perfettamente i punti di debolezza nella sistemazione di Banville, pur oggetto di nuova attenzione accademica a partire dagli anni '90, e soprattutto studiato, sia dal punto di vista biografico che per quanto riguarda il ruolo nella storia letteraria, da Philippe ANDRÈs (vedi scheda su «Studi francesi» n. 159). L'A. si propone invece una riflessione estetica sull'evoluzione dell'opera, per meglio delineare le intersezioni di Romantisme e Parnasse e cogliere la portata del fenomeno del neo ellenismo sia attraverso le raccolte greche e neo greche sia nei suoi collegamenti con la vita moderna attraverso Odes funambulesques e Occidentales. La ricontestualizzazione delle poesie elleniche permette all'A. di misurare la specificità di Banville nei confronti di quell'École païenne fustigata nel '52 da Baudelaire (vedi P. TORTONESE su «Studi francesi» n. 159).

2 In un secondo tempo l'A. si sofferma in modo particolare sulla rappresentazione della Grecia, per indagarne i modelli referenziali e le forme della rielaborazione mitica anche come mito criptico soggiacente alle raccolte moderne.

3 L'A. individua nel bagaglio scolastico di Banville larga parte dei suoi riferimenti al mondo classico greco e latino, ma riconosce la grande suggestione esercitata dai lavori di Creuzer e Ottfried Müller e soprattutto Ménard, di cui Banville parafrasava interi paragrafi del Polythésime hellénique.

4 L'analisi delle presenze del mito della Grecia antica nella produzione di Banville diventa pretesto per un'ampia ricognizione storica dal Romanticismo al Secondo Impero, in cui l'A. indaga quegli elementi di ellenismo che persistono anche nei primi decenni del XIX secolo, in convivenza con il nuovo impulso dato alla religione cristiana e alle sue figure. 
Ricorda l'importanza a questo proposito determinante della pubblicazione nel 1819 delle poesie di André Chénier, e come il mito dell'Ellade sia sopravvissuto anche grazie all'entusiasmo filologico e archeologico suscitato dalle continue scoperte in entrambi i campi nonché attraverso i viaggi in Oriente, risultando presente nello stesso Hugo, soprattutto a partire dalle Orientales. Quando l'A. si concentra di nuovo su Banville, ha già perfettamente delineato il quadro di tutta l'epoca. Nel presentare le presenze elleniche in Banville, l'A. usa il termine felice di «hellénisme par ricochet» a indicare quel processo di mediazione per cui l'immagine della Grecia viene filtrata dalla tradizione successiva, ad esempio attraverso Ronsard. In un secondo tempo l'A. prende in considerazione $\mathrm{i}$ rapporti con $\mathrm{i}$ grandi autori della sua epoca, da Baudelaire a Verlaine a Rimbaud a Mallarmé, misurando altresì il diverso peso poetico delle immagini classiche nel corso dell' evoluzione politica di Banville che, ottenuto il favore di Napoléon III, si esercita in poesie d'occasione in cui l'antichità diventa solo uno strumento retorico. Il volume è corredato da un'ampia bibliografia. 